\title{
Magnesium Sulfate Nebulizer versus Ketamine Nebulizer in Decreasing Incidence and Severity of Post Operative Sore Throat with Endotracheal Intubation in Adults
}

\author{
Essam Ali Mostafa, Ahmed Saied Abdel Rahman and Mahmoud Darwish Mahmoud* \\ Anesthesia and Intensive Care Medicine and Pain Management Department, Faculty of Medicine, Al- \\ Azhar University \\ *Corresponding Author: Mahmoud Darwish Mahmoud, Phone No.: (+2) 01002013816, E-mail: \\ mahmoud.darwish.med@gmail.com
}

\begin{abstract}
Background: Endotracheal intubation is the prominent cause of airway mucosal injury which results in postoperative sore throat (POST), with an incidence of $21 \%-65 \%$. Although this complication is minor, if left unresolved, it produces significant agony and annoyance to the patient.

Aim of the Work: to compare efficacy of magnesium/nebulizer versus ketamine nebulizer in decreasing postoperative sore throat incidence, severity and duration with fixed endotracheal tube intra cuff pressure at or below $20 \mathrm{~cm} \mathrm{H}_{2} \mathrm{O}$ using handheld tracheal cuff pressure monitor in adults ASA (American Society of Anesthesiologists) I-II in 20-60 years age group of either sex in operations less than 2 hours. Methodology: our study included 90 adult patients, status I-II (ASA I-II) in the age group 20-60 years, of either sex undergoing operation under general anesthesia (GA) scheduled for a day case surgery and operation time less than 2 hours with fixation of endotracheal tube cuff at $20 \mathrm{~cm} \mathrm{H}_{2} \mathrm{O}$ using hand held tracheal cuff pressure monitor (Pressure Gauge) and checked every half hour till end of surgery and maintained at or below $20 \mathrm{~cm} \mathrm{H}_{2} \mathrm{O}$.
\end{abstract}

Results: Our study showed reduction in POST incidence and severity after preoperative magnesium sulfate nebulization in all time points $0,2,4,8,12$ and 24 hours postoperative, so it was proved that magnesium nebulizer has great role in reduction of incidence, severity and duration of POST.

Conclusion: we concluded that preoperative magnesium sulfate nebulization reduce incidence and severity of POST and it is more effective than preoperative ketamine nebulization.

Keywords: Magnesium Sulfate Nebulizer - Ketamine Nebulizer - Post Operative Sore Throat INTRODUCTION

Endotracheal intubation is the prominent cause of airway mucosal injury which results in postoperative sore throat (POST), with an incidence of $21 \%-65 \%$. Although this complication is minor, if left unresolved, it produces significant agony and annoyance to the patient ${ }^{[1]}$.

It is considered an important complication as it may increase incidence of postoperative morbidity as hoarseness of voice and dysphagia that cause patient dissatisfaction and discomfort. It may be unresolved for few days postoperative and prolong hospital stay especially in day-case surgeries. .2$]$

Multiple pharmacological and non pharmacological methods have been used to decrease the incidence of POST duration and severity. ${ }^{[2]}$ The pharmacological methods used to reduce POST include use of beclomethasone gel, lidocaine spray, intravenous dexamethasone-ketamine gargle or nebulizer, oral magnesium lozenge or nebulizer [3-11].

The non-pharmacological methods include smaller sizes of tracheal tubes, careful airway manipulation, intubation after complete muscle relaxation, minimizing the number of

laryngoscopy trials for intubation, fixation of endo tracheal tube intra cuff pressure at or below $20 \mathrm{~cm} \mathrm{H}_{2} \mathrm{O}$, gentle pharyngeal suctioning under vision and extubation when the tracheal tube cuff is fully deflated to avoid coughing during extubation [6]. All these methods have been reported to decrease the incidence of POST..$[1,2, \mathbf{6}]$

It is known that N-methyl-D-aspartate (NMDA) receptors have an important role in nociception and inflammation in human body. NMDA receptors present in peripheral nerves and the central nervous system. $[$ [9].

Ketamine is N-methyl-D-aspartate (NMDA) receptor antagonist and has been used as a gargle or nebulizer for reducing the incidence and severity of POST due to its antinociceptive and anti-inflammatory effects. $\frac{[7,8]}{}$

Ketamine nebulization is superior to ketamine gargle as the latter is used in larger volume that may carry risk of aspiration if accidentally swallowed in addition to its bitter taste. [10]

Magnesium is also another NMDA receptor antagonist that plays an important role to decrease incidence of POST. It is used as oral 
lozenge or nebulizer, it is accessible and easily available in hospitals and nebulization will be simple, cost-effective method to decrease POST symptoms. $\frac{[5,11]}{[}$

The efficacy of preoperative nebulization of magnesium sulfate was assessed and found that the incidence and severity of POST were reduced at rest and on swallowing through 24 hours post extubation. [11]

Some studies showed that ketamine and magnesium can be used for attenuation of postoperative sore throat $[\mathbf{1 0 , 1 1 ]}$

A previous study had shown comparison between magnesium and ketamine gargle efficacy in decreasing the incidence of POST ${ }^{[12]}$, but ketamine nebulization is superior to ketamine gargle. 10$]$

In this study, magnesium nebulization is compared to ketamine nebulization in patients undergoing elective operations less than 2 hours and endotracheal intra cuff pressure will be measured every 30 minutes by manometer and fixed at $20 \mathrm{~cm} \mathrm{H}_{2} \mathrm{O}$.

\section{AIM OF THE WORK}

The study aims to compare efficacy of magnesium/ nebulizer versus ketamine nebulizer in decreasing postoperative sore throat incidence, severity and duration with fixed endotracheal tube intra cuff pressure at or below $20 \mathrm{CmH}_{2} \mathrm{O}$ using handheld tracheal cuff pressure monitor (Pressure Gauge) in adults ASA I-II in 20-60 years age group of either sex in operations less than 2 hours.

\section{METHODOLOGY}

\section{Study design}

A randomized double-blinded controlled trial.

\section{Study setting and location}

This study was conducted at Damanhour Oncology Center.

\section{Study population}

90 patients belonging to American Society of Anesthesiologists physical status I-II (ASA I-II) in the age group 20-60 years, of either sex undergoing operation under general anesthesia (GA) scheduled for a day case surgery and operation time less than 2 hours.

Consenting patients were randomly allocated to either of three study groups:

- Group Magnesium (M): 30 patients received pre-operative nebulization with $250 \mathrm{mg}$ magnesium sulfate $(2.5 \mathrm{ml})$ with $2.5 \mathrm{ml}$ isotonic saline.
- Group Ketamine (K): 30 patients received pre-operative nebulization with $\mathbf{2 5} \mathbf{~ m g}$ ketamine $(0.5 \mathrm{ml})$ with $4.5 \mathrm{ml}$ isotonic saline.

- Group Saline(S): 30 patients received preoperative nebulization with $\mathbf{5} \mathbf{~ m l}$ normal isotonic saline.

\section{Eligibility Criteria Inclusion criteria}

- Patients belonging to American Society of Anesthesiologists physical status I-II.

- Age group ( $\geq 20-\leq 60$ years).

- Both sex.

- Operation time less than 2 hours.

\section{Exclusion criteria}

- American Society of Anesthesiology (ASA) physical status $\geq$ III.

- Known allergy or hypersensitivity to magnesium or ketamine.

- Difficult intubation (Mallampati> III) $[13]$ or multiple trials of intubation.

- Surgical manipulation of airway.

- Head and neck surgeries.

- Duration of operation (less than 30 minutes or more than 120 minutes).

- Heavy smokers (20 packs /week).

- Suction more than once under vision.

- Post extubation laryngeal spasm.

- Renal dysfunction (creatinine > 1.2, Bun >20)

- Heart block.

- Muscle disease.

- Pre-existing sore throat or respiratory tract infection within 2 weeks.

- High pressure low volume endotracheal tubes.

- Age less than 20 and more than 60 years.

\section{Study Procedures \\ Randomization}

Randomization was done via a computer generated numbers and concealed by serially numbered, opaque and sealed envelopes. The details of series were unknown to the investigators and the group assignment was kept in a set of concealed envelopes each bearing only the case number on the outside. Prior to start of study the appropriate numbered envelopes were opened by the nurse, the card determined the patient group.

\section{Study outcomes Primary outcome}


The primary outcome was to observe the incidence of POST at $4^{\text {th }}$ hour postoperative. Secondary outcomes

- Incidence of POST at $0,2,8,12,24$ hours.

- Severity and duration of POST.

- The hemodynamics recording (blood pressure and heart rate) was done prenebulization $\mathrm{T} 0$ (base line), postnebulization T1(pre-induction), post intubation $\mathrm{T} 2$, intraoperative every 15 minutes till the end of surgery $\mathrm{T} 3 / 15$ minutes and postoperative $\mathrm{T} 4$ on arrival of post-anesthesia care unit.

- Nausea and vomiting.

- Systemic side effects of ketamine (sedation, hallucinations, nystagmus).

\section{Statistical Analysis}

\section{Sample size}

As considered the primary outcome of our study, sample size calculation was done using the comparison of occurrence of sore throat at $4^{\text {th }}$ hour among adult cases treated with magnesium sulphate nebulizer, ketamine nebulizer, and normal saline. Calculation was done based on comparing 3 proportions from independent samples in a prospective study using Chi square test, the $\alpha$-error level was fixed at 0.05 , the power was set at $80 \%$ and the groups ratio was set at 1 .

As previously published, $[11,12]$ the occurrence of post-operative sore throat in cases treated with magnesium sulfate was $10 \%$, in ketamine treated cases it was $50 \%$ while it was $22 \%$ in saline treated cases. According to the calculated effect size (0.3), the minimum optimum sample size should be 25 participants in each group. The number was increased to 30 patients per group to compensate possible dropouts.

\section{Statistical analysis}

SPSS software was used for data analysis. Categorical data was expressed as frequencies and percentages and was analyzed using chi-square test. Continuous data was checked for normality using Shapiro-Wilk test and analyzed using unpaired $\mathrm{t}$ test, Mann Whitney test, and analysis of variance test (ANOVA) as appropriate_P value less than 0.05 was considered significant.

\section{RESULTS}

POST score $0,2,4,8,12$ and $24 \mathrm{~h}$ was statistically significant between groups at $0 \mathrm{hr}$ (p value 0.005$), 2 \mathrm{hr}$ (p value 0.002$)$, $4 \mathrm{~h}(\mathbf{p}$ value 0.000$)$, $8 \mathrm{hr}$ (p value 0.000$), 12 \mathrm{hr}(\mathrm{p}$ value 0.023 ) and $24 \mathrm{hr}$ (p value 0.001 ) as shown in table 1.

Table (1): POST four grade scale parameters and P value

\begin{tabular}{|c|c|c|c|c|c|c|c|c|c|c|c|c|c|c|c|c|c|c|c|}
\hline & \multicolumn{6}{|c|}{ S group } & \multicolumn{6}{|c|}{ M group } & \multicolumn{6}{|c|}{ K group } & \multirow{2}{*}{$\begin{array}{l}\mathbf{P} \text { - } \\
\text { value }\end{array}$} \\
\hline & Mean & & $\begin{array}{l}\text { Std. } \\
\text { Deviation }\end{array}$ & $\begin{array}{l}\text { Mini } \\
\text { mum }\end{array}$ & $\begin{array}{l}\text { Maxi } \\
\text { mum }\end{array}$ & $\begin{array}{l}\text { Medi } \\
\text { an }\end{array}$ & $\begin{array}{l}\text { Mea } \\
\text { n }\end{array}$ & $\mathbf{N}$ & \begin{tabular}{|l|} 
Std. \\
Deviation
\end{tabular} & $\begin{array}{l}\text { Mini } \\
\text { mum }\end{array}$ & $\begin{array}{l}\text { Maxi } \\
\text { mum }\end{array}$ & $\begin{array}{l}\text { Medi } \\
\text { an }\end{array}$ & Mean & $\overline{\mathbf{N}}$ & Std. Deviat & $\begin{array}{l}\text { Min } \\
\text { imu } \\
\text { m }\end{array}$ & $\begin{array}{l}\text { Maxi } \\
\text { num }\end{array}$ & $\begin{array}{l}\text { Media } \\
\text { n }\end{array}$ & \\
\hline POST 0 & 2.47 & 30 & 0.900 & $\mathbf{0}$ & 3 & 2.00 & 1.93 & 30 & 0.785 & $\mathbf{0}$ & 3 & 2.00 & 1.97 & 30 & 0.669 & $\mathbf{0}$ & 2 & 2.00 & 0.016* \\
\hline POST 2h & 1.83 & 30 & 0.791 & 0 & 2 & 2 & 1.43 & 30 & 0.626 & 0 & 2 & 2 & 1.83 & 30 & 0.699 & 0 & 2 & 1 & 0.047* \\
\hline POST 4h & 1.70 & 30 & 0.794 & 0 & 2 & 1.5 & 1.10 & 30 & 0.305 & 0 & 1 & 1 & 1.47 & 30 & 0.507 & $\mathbf{0}$ & 1 & 1 & $0.000 *$ \\
\hline POST 8h & 1.40 & 30 & 0.498 & $\mathbf{0}$ & 1 & 1 & 1.00 & 30 & .000 & $\mathbf{0}$ & 1 & 1 & 1.13 & 30 & 0.346 & $\mathbf{0}$ & 1 & 1 & $0.000 *$ \\
\hline $\begin{array}{l}\text { POST } \\
12 \mathrm{~h} \\
\end{array}$ & 1.20 & 30 & 0.407 & $\mathbf{0}$ & 1 & 1 & 1.00 & 30 & .000 & $\mathbf{0}$ & $\mathbf{0}$ & 1 & 1.03 & 30 & 0.183 & $\mathbf{0}$ & 1 & $\mathbf{0}$ & $0.007 *$ \\
\hline $\begin{array}{l}\text { POST } \\
24 h\end{array}$ & 1.10 & 30 & 0.305 & $\mathbf{0}$ & 1 & 1 & 1.00 & 30 & .000 & $\mathbf{0}$ & $\mathbf{0}$ & 1 & 1.00 & 30 & .000 & $\mathbf{0}$ & $\mathbf{0}$ & 1 & 0.049* \\
\hline
\end{tabular}

There is significant $\mathrm{p}$ value and statistical difference between $\mathrm{M}$ group and $\mathrm{K}$ group POST at $2 \mathrm{hr}$ ( $\mathbf{p}$ value 0.023 ), $4 \mathrm{hr}$ ( $\mathbf{p}$ value 0.001 ) and $8 \mathrm{hr}$ (p value 0.044 ) postoperative between $\mathrm{M}$ group and $S$ group POST at $0 \mathrm{hr}$ (p value 0.016 ), $2 \mathrm{hr}$ (p value 0.034$), 4 \mathrm{hr}$ (p value $\mathbf{0 . 0 0 3}$ ), $8 \mathrm{hr}$ (p value 0.001 ) and $12 \mathrm{hr}$ ( $\mathbf{p}$ value 0.009 ) postoperative and also between $S$ and $K$ group at 8 hour ( $\mathbf{p}$ value 0.018 ) and $12 \mathrm{hr}$ (p value 0.041) postoperative as shown in table 2.

Table (2): $\mathrm{P}$ value between groups in comparison in each other regarding POST scale

\begin{tabular}{|l|c|c|c|c|c|c|}
\hline & $\begin{array}{c}\text { POST } \\
\mathbf{0}\end{array}$ & $\begin{array}{c}\text { POST } \\
2 \mathrm{~h}\end{array}$ & $\begin{array}{c}\text { POST } \\
4 \mathrm{~h}\end{array}$ & $\begin{array}{c}\text { POST } \\
8 \mathrm{~h}\end{array}$ & $\begin{array}{c}\text { POST } \\
12 \mathrm{~h}\end{array}$ & $\begin{array}{c}\text { POST } \\
24 \mathrm{~h}\end{array}$ \\
\hline $\begin{array}{l}\text { P value between M } \\
\text { group and K group }\end{array}$ & $\underline{\mathbf{0 . 8 3 3}}$ & $\underline{\mathbf{0 . 0 2 3}}$ & $\underline{\mathbf{0 . 0 0 1}}$ & $\underline{\mathbf{0 . 0 4 4}}$ & $\underline{\mathbf{0 . 3 7 3}}$ & $=$ \\
\hline $\begin{array}{l}\text { P value between M } \\
\text { group and S group }\end{array}$ & $\underline{\mathbf{0 . 0 1 6}}$ & $\underline{\mathbf{0 . 0 3 4}}$ & $\underline{\mathbf{0 . 0 0 3}}$ & $\underline{<.001}$ & $\underline{\mathbf{0 . 0 0 9}}$ & $\underline{\mathbf{0 . 0 7 7}}$ \\
\hline $\begin{array}{l}\text { P value between K } \\
\text { group and S group }\end{array}$ & $\underline{\mathbf{0 . 0 1 8}}$ & $\underline{\mathbf{1 . 0 0 0}}$ & $\underline{\mathbf{0 . 1 8 6}}$ & $\underline{\mathbf{0 . 0 1 8}}$ & $\underline{\mathbf{0 . 0 4 1}}$ & $\underline{\mathbf{0 . 0 7 7}}$ \\
\hline
\end{tabular}

“*”denotes that $\mathrm{p}$ value is significant 
Table (3): Incidence of POST and number of patients with percentage of patient number in relation to total number of patients

\begin{tabular}{|l|l|l|l|l|l|l|l|}
\hline & & POST 0 & POST 2h & POST 4h & POST 8h & POST 12h & POST 24h \\
\hline \multirow{2}{*}{$\mathrm{S}$} & 0 & $3(3.3 \%)$ & $12(13.3 \%)$ & $15(16.7 \%)$ & $26(28.9 \%)$ & $24(26.7 \%)$ & $27(30 \%)$ \\
\cline { 2 - 8 } & 1 & $27(30 \%)$ & $18(20 \%)$ & $15(16.7 \%)$ & $4(13.3 \%)$ & $6(6.6 \%)$ & $3(3.3 \%)$ \\
\hline & & & & & & & \\
\hline \multirow{2}{*}{$\mathrm{M}$} & 0 & $9(10 \%)$ & $19(21.1 \%)$ & $27(30 \%)$ & $30(33.3 \%)$ & $30(33.3 \%)$ & $30(33.3 \%)$ \\
\hline & 1 & $21(23.3 \%)$ & $11(12.2 \%)$ & $3(3.3 \%)$ & 0 & 0 & 0 \\
\hline \multirow{2}{*}{$\mathrm{K}$} & 0 & $7(7.7 \%)$ & $10(11.1 \%)$ & $16(17.8 \%)$ & $26(28.9 \%)$ & $29(32.2 \%)$ & $30(33.3 \%)$ \\
\cline { 2 - 8 } & 1 & $23(25.6 \%)$ & $20(22.2 \%)$ & $14(15.6 \%)$ & $4(4.4 \%)$ & $1(1.1 \%)$ & 0 \\
\hline
\end{tabular}

Number of patients and percentage according to severity of POST on POST four grade scale showing statistical difference between groups at $0 \mathrm{hr}$ (p value 0.016), $2 \mathrm{hr}$ (p value $\mathbf{0 . 0 0 1}$ ), $4 \mathrm{hr}$ (p value 0.001 ) and $8 \mathrm{hr}$ (p value $\mathbf{0 . 0 0 9}$ ) postoperative as shown in table 4 .

Table (4): Severity of POST and number of patients

\begin{tabular}{|c|c|c|c|c|c|c|c|c|}
\hline \multirow{2}{*}{\multicolumn{2}{|c|}{ grade }} & \multicolumn{2}{|c|}{$\mathrm{S}$ group } & \multicolumn{2}{|c|}{$M$ group } & \multicolumn{2}{|c|}{$\mathrm{K}$ group } & \multirow{2}{*}{ P-value } \\
\hline & & No. & $\%$ & No. & $\%$ & No. & $\%$ & \\
\hline \multirow{4}{*}{ POST 0} & 0 & 3 & $10.0 \%$ & 9 & $30 \%$ & 7 & $23.3 \%$ & \multirow{4}{*}{0.107} \\
\hline & 1 & 15 & $50 \%$ & 15 & $50.0 \%$ & 17 & $56.7 \%$ & \\
\hline & 2 & 7 & $23.3 \%$ & 5 & $16.7 \%$ & 6 & $20.0 \%$ & \\
\hline & 3 & 5 & $16.7 \%$ & 1 & $3.3 \%$ & 0 & $0.0 \%$ & \\
\hline \multirow{4}{*}{ POST 2h } & 0 & 12 & $40 \%$ & 19 & $63.7 \%$ & 10 & $33.3 \%$ & \multirow{4}{*}{0.270} \\
\hline & 1 & 11 & $36.7 \%$ & 9 & $30.0 \%$ & 15 & $50 \%$ & \\
\hline & 2 & 7 & $23.3 \%$ & 2 & $6.7 \%$ & 5 & $16.7 \%$ & \\
\hline & 3 & 0 & 0 & 0 & 0 & 0 & 0 & \\
\hline \multirow{4}{*}{ POST 4h } & 0 & 15 & $50.0 \%$ & 27 & $90 \%$ & 16 & $53.3 \%$ & \multirow{4}{*}{$0.001 *$} \\
\hline & 1 & 9 & $30 \%$ & 3 & $10 \%$ & 14 & $46.7 \%$ & \\
\hline & 2 & 6 & $20 \%$ & 0 & 0 & 0 & 0 & \\
\hline & 3 & 0 & 0 & 0 & 0 & 0 & 0 & \\
\hline \multirow{4}{*}{ POST 8h } & 0 & 18 & $60 \%$ & 30 & $100.0 \%$ & 26 & $86.7 \%$ & \multirow{4}{*}{$0.009 *$} \\
\hline & 1 & 12 & $40 \%$ & 0 & $0.0 \%$ & 4 & $13.3 \%$ & \\
\hline & 2 & 0 & 0 & 0 & 0 & 0 & 0 & \\
\hline & 3 & 0 & 0 & 0 & 0 & 0 & 0 & \\
\hline \multirow{4}{*}{ POST $12 \mathrm{~h}$} & 0 & 24 & $80 \%$ & 30 & $100.0 \%$ & 29 & $96.7 \%$ & \multirow{4}{*}{0.142} \\
\hline & 1 & 6 & $20 \%$ & 0 & $0.0 \%$ & 1 & $3.3 \%$ & \\
\hline & 2 & 0 & 0 & 0 & 0 & 0 & 0 & \\
\hline & 3 & 0 & 0 & 0 & 0 & 0 & 0 & \\
\hline \multirow{4}{*}{ POST $24 \mathrm{~h}$} & 0 & 27 & $90 \%$ & 30 & $100.0 \%$ & 30 & $100.0 \%$ & \multirow{4}{*}{0.400} \\
\hline & 1 & 3 & $10 \%$ & 0 & $0.0 \%$ & 0 & $0.0 \%$ & \\
\hline & 2 & 0 & $0.0 \%$ & 0 & $0.0 \%$ & 0 & $0.0 \%$ & \\
\hline & 3 & 0 & $0.0 \%$ & 0 & $0.0 \%$ & 0 & $0.0 \%$ & \\
\hline
\end{tabular}

*"denotes that $\mathrm{p}$ value is significant

There was statistical difference $(\mathrm{p}<0.05)$ between $M$ group and $K$ group at 4 hr(p value $\mathbf{0 . 0 0 2}), 8$ hours (p value 0.038) postoperative while between $M$ group and $S$ group at $4 \mathrm{hr}(\mathbf{p}$ value 0.002$), 8$ $\mathrm{hr}(\mathbf{p}$ value 0.000) and $12 \mathrm{hr}(\mathbf{p}$ value 0.010) postoperative and between $\mathrm{S}$ group and $\mathrm{K}$ group at $4 \mathrm{hr}$ (p value 0.028), $8 \mathrm{hr}(\mathbf{p}$ value 0.020 ) and 12 hours (p value 0.044$)$ postoperative as shown in table 16 .

Table 5. P value between groups in comparison in each other regarding severity of POST using 4 grade POST scale 


\begin{tabular}{|c|c|c|c|c|c|c|}
\hline & $\begin{array}{c}\text { POST } \\
0\end{array}$ & $\begin{array}{c}\text { POST } \\
2 \mathrm{~h}\end{array}$ & $\begin{array}{c}\text { POST } \\
4 h\end{array}$ & $\begin{array}{c}\text { POST } \\
8 \mathrm{~h}\end{array}$ & $\begin{array}{c}\text { POST } \\
12 \mathrm{~h}\end{array}$ & $\begin{array}{c}\text { POST } \\
24 h\end{array}$ \\
\hline $\begin{array}{l}P \text { value between } M \\
\text { group and } K \text { group }\end{array}$ & $\underline{\mathbf{0 . 6 9 0}}$ & $\underline{0.061}$ & $\underline{\mathbf{0 . 0 0 2}}$ & $\underline{\mathbf{0 . 0 3 8}}$ & $\underline{\mathbf{0 . 3 1 3}}$ & - \\
\hline $\begin{array}{l}P \text { value between } M \\
\text { group and } S \text { group }\end{array}$ & $\underline{\mathbf{0 . 1 1 2}}$ & $\underline{\mathbf{0 . 1 0 2}}$ & $\underline{0.002}$ & $\underline{\mathbf{0 . 0 0 0}}$ & $\underline{\mathbf{0 . 0 1 0}}$ & $\underline{\mathbf{0 . 0 7 6}}$ \\
\hline $\begin{array}{l}P \text { value between } K \\
\text { group and } S \text { group }\end{array}$ & $\underline{0.078}$ & $\underline{0.568}$ & $\underline{0.028}$ & $\underline{0.020}$ & $\underline{0.044}$ & $\underline{0.076}$ \\
\hline
\end{tabular}

\section{DISCUSSION}

Postoperative sore throat (POST) is a common postoperative complication in patients undergoing operations under general anesthesia using endotracheal tubes and also supraglottic devices. It is considered as one of the most common undesirable anesthesia-associated problems 2$]$.

Multiple pharmacological and non pharmacological methods have been used to decrease POST incidence, duration and severity. $[2,6]$

This study compared efficacy of preoperative nebulization of magnesium with ketamine and normal saline as control group to reduce POST incidence and severity at $0,2,4$, 8,12 and 24 hour postoperative using 4 grade POST scale.

Our rationale of using the nebulized form of ketamine and magnesium rather than its other forms (oral, IV, gargle) was primarily oriented for safety and ease of administration to the patient in the immediate pre-operative period to avoid all those disadvantages of gargling and systemic absorption of drugs and got the best benefit from their local effects on throat and upper airway. $\stackrel{[10]}{[}$

Regarding incidence of POST, In our study, there was statistical difference between groups regarding incidence of POST.

There was statistical difference between $\mathrm{M}$ group and $\mathrm{K}$ group at $0,2,4$, and 8 hours postoperative while between $\mathrm{M}$ group and $\mathrm{S}$ group at all hours postoperative and between $\mathrm{S}$ group and $\mathrm{K}$ group at 24 hours postoperative.

In agreement with our study, Houman et al. ${ }^{[14]}$ concluded that number of patients with sore throat were significantly lower in the magnesium group compared to ketamine group at $2 \mathrm{hr}(\mathbf{P}=\mathbf{0 . 0 3 2}), 4 \mathrm{hr}(\mathbf{P}=\mathbf{0 . 0 2})$ and 24 hours $(\mathbf{P}=\mathbf{0 . 0 1})$ after operation, However incidence of postoperative sore throat in two groups after using magnesium or ketamine gargle were not significantly different at arrival in the recovery room at 0 hour $(\mathbf{P}=\mathbf{0 . 0 8 5})$ unlike our study. this results' difference between this study and our study may be due to using different measurement tool for POST assessment as in Houman et al. [14] throat pain score was measured by visual analogue scale (VAS) while in our study we used POST four grade scale, and using different method of administration gargling versus nebulization in our study and also Houman et al. ${ }^{[14]}$ worked on 100 cases divided into two groups of emergency operations and using suxamethonium as muscle relaxant which was one of risk factors that increase incidence and severity of POST while in our study, we worked on 90 cases divided into three groups of elective operations and we used atracurium for complete muscle relaxation.

In agreement with our study, Gupta et al. [15] assessed magnesium nebulizer to decrease POST incidence and severity at rest and on swallowing and side-effects at $0 \mathrm{hr}, 2 \mathrm{hr}$, $4 \mathrm{hr}$, and $24 \mathrm{~h}$ in the postoperative period. Incidence and severity of POST were found to be reduced at rest and on swallowing for all time points.

In contrast to our study, Monu et al. $\stackrel{[1]}{\square}$ assessed the efficacy of preoperative nebulization of magnesium sulfate in comparison to saline nebulization and found that there was no significant difference in POST at rest at $0 \mathrm{hr}(\boldsymbol{P}$ $=\mathbf{0 . 6 0 3}), 2 \mathrm{hr}(\boldsymbol{P}=\mathbf{0 . 2 9 8})$ and $4 \mathrm{hr}(\boldsymbol{P}=\mathbf{0 . 1 0 1})$ between normal saline and magnesium sulfate unlike our study that showed significant statistical difference in all time points between $\mathrm{M}$ and $\mathrm{S}$ group regarding incidence and severity of POST however there was significant statistical difference at $24 \mathrm{~h}(\boldsymbol{P}=\mathbf{0 . 0 1 2})$ like our study.

Our study concluded that magnesium sulfate significantly reduces the incidence of POST compared to normal saline. This difference between results may be due to using larger doses of magnesium $250 \mathrm{mg}$ in our study while $225 \mathrm{mg}$ was used in Monu et al. $\stackrel{[11]}{\text { study. }}$

Monu et al. [11] and Gupta et al. [15] studies were superior to our study as POST was assessed not only at rest but also on swallowing. 
In contrast to our study, In a study done by Ahuja et al. [10] comparing ketamine nebulizer with saline nebulizer to decrease of POST incidence and severity, it was done on 108 patients, there was significant difference occurred at $2 \mathrm{hr}(\boldsymbol{P}=\mathbf{0 . 0 1})$ and 4 hour $(\mathbf{p}=\mathbf{0 . 0 3})$ postoperative, while our study showed significant and statistical difference between $\mathrm{S}$ and $\mathrm{K}$ group at 24 hour $(\mathbf{p = 0 . 0 1})$ postoperative regarding incidence.

Regarding severity of POST, In our study, number of patients and percentage according to severity of POST using POST four grade scale showed statistical difference between groups at all hours postoperative.

There was statistical difference $(\mathbf{p}<\mathbf{0 . 0 5})$ between $\mathrm{M}$ group and $\mathrm{K}$ group at 4 , and 8 hours postoperative while between $\mathrm{M}$ group and $\mathrm{S}$ group at 4,8 and 12 hours postoperative and between $S$ group and $\mathrm{K}$ group at 4,8 and 12 hours postoperative.

In agreement with our study, in Houman et al. [14] study sore throat pain severity was assessed and there was statistical difference between two groups of study at $2 \mathrm{hr}$ $(\mathbf{P}=\mathbf{0 . 0 1 9}), 4$ hours $(\mathbf{P}=\mathbf{0 . 0 2 8})$ postoperative. However unlike our study, there was significant statistical difference at $0 \mathrm{hr}$ and 24 hours after operation and this result's difference may be attributed to using different measurement tool for POST assessment in Houman et al. study $[14]$ as throat pain score was measured by visual analogue scale (VAS) while we used POST four grade scale and also different method of administration gargling versus nebulization in our study.

In agreement with our study, in a study done by Ahuja et al. [10] comparing ketamine nebulizer with saline nebulizer to decrease incidence and severity of POST, it was done on 108 patients, there was significant difference at 2 hour $(\mathbf{p = 0 . 0 2})$ postoperative, while our study showed statistical difference between $\mathrm{S}$ and $\mathrm{K}$ group at 4,8 and 24 hours postoperative regarding severity of POST.

Regarding Heart Rate, In our study, there was statistical difference between groups at post nebulization $\mathrm{T} 1$, post intubation $\mathrm{T} 2$, 15 min post intubation $\mathrm{T} 3$ and postoperative $\mathrm{T} 4$ but this difference had no clinical significance. There was no statistical difference at Prenebulization $\mathrm{T} 0$.

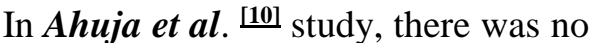
statistical difference regarding heart rate between magnesium gargle and ketamine gargle. These results were also found by Houman et al. [14].

Regarding Mean Arterial Blood Pressure, in our study, there was statistical difference between groups at post nebulization $\mathrm{T} 1$, post intubation $\mathrm{T} 2,15 \mathrm{~min}$ post intubation $\mathrm{T} 3$ and postoperative T4 but this difference had no clinical significance.

There was no statistical significant difference between the groups at prenebulization $\mathrm{T} 0$.

While in Ahuja et al. $\frac{10]}{[}$ study, systolic blood pressure was measured intraoperatively and not mean arterial blood pressure as our study. There was no statistical difference regarding systolic blood pressure between magnesium gargle and ketamine gargle.

Regarding times of assessment of POST, In our study, it was 5 times at $\left(0,2^{\text {nd, }} 4^{\text {th, }}\right.$ $8^{\text {th }}$ and $\left.24^{\text {th }}\right)$ hour postoperative while in Houman et al. ${ }^{[14]}$, Gupta et al. ${ }^{[15]}$ and Monu study 11$]$ it was at $\left(0,2^{\text {nd, }} 4^{\text {th }}\right.$ and $\left.24^{\text {th }}\right)$ hour postoperative while in Ahuja et al. ${ }^{[10]}$ study it was at $\left(0,2^{\text {nd, }} 4^{\text {th, }} 6^{\text {th, }} 8^{\text {th, }} 12^{\text {th }}\right.$ and $\left.24^{\text {th }}\right)$ hour hours postoperative.

Our study assessed patients by questionnaire about the side effects of ketamine present e.g nausea, vomiting, nystagmus and hallucinations and it was found that no hallucination or nystagmus occurred.

Drawbacks and limitations of our study include measurement of serum magnesium and serum ketamine and there was no assessment of POST during swallowing in our study.

\section{CONCLUSION}

We concluded that preoperative magnesium sulfate nebulization reduces incidence and severity of POST and it is more effective than preoperative ketamine nebulization.

\section{REFERENCES}

1. Derlin T, Revathy B, Nimeeliya $Z$ et al. (2018): Preoperative ketamine nebulization attenuates the incidence and severity of postoperative sore throat: A randomized controlled clinical trial. Saudi J Anaesth., 12(3): 440-445.

2. Higgins PP, Chung $F$ and Mezei $G$ (2002): Postoperative sore throat after ambulatory surgery. Br J Anaesth., 88(4): 582-597.

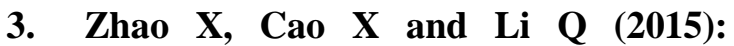
Dexamethasone for the prevention of postoperative sore throat. J ClinAnesth., 27(4): 45-50. 
4. Maruyama K, Sakai H, Miyazawa $\mathrm{H}$ et al. (2004): Laryngotracheal application of lidocaine spray increases the incidence of postoperative sore throat after total intravenous anesthesia. J Anesth., 40(8): 18-237.

5. Borazan H, Kececioglu A, Okesli S et al. (2012): Oral magnesium lozenge reduces postoperative sore throat: A randomized, prospective, placebo-controlled study. Anesthesiology, 117(8): 512-524.

6. Ratnaraj J, Todorov A, McHugh T et al. (2002): Effects of decreasing endotracheal tube cuff pressures during neck retraction for anterior cervical spine surgery. Neurosurg., 97(9): 176-183.

7. Chan L, Lee ML and Lo YL (2010): Postoperative sore throat and ketamine gargle. Br J Anaesth., 5(3): 97-105.
8. Canbay O, Celebi N, Sahin A et al. (2008): Ketamine gargle for attenuating postoperative sore throat. Br J Anaesth., 3: 100-490.

9. Lin CY, Tsai PS, Hung YC et al. (2010): L-type calcium channels are involved in mediating the anti-inflammatory effects of magnesium sulphate. $\mathrm{Br} \mathrm{J}$ Anaesth., 104(9): 44-51.

10. Ahuja V, Mitra $S$ and Sarna $R$ (2015): Nebulized ketamine decreases incidence and severity of post-operative sore throat. Indian J Anaesth., 59(3): 37-42.

11. Monu Y, Nitish $C$, Ramachandran $G$ et al. (2016): Effect of magnesium sulfate nebulization on the incidence of postoperative sore throat, J Anaesthesiol Clin Pharmacol., 32(2): 168-171.

12. Andreas E (2001): Concise anatomy for Anaesthesia. London. Cambridge University Press. Edition 1.

13. Mescher AL (2005): The Respiratory System. Mescher AL (Edition 1): Junqueira's Basic Histology: Text \& Atlas. Chapter 17.

14. Houman T, Seyed AM and Alireza $\mathbf{F}$ (2015): Magnesium and Ketamine Gargle and Postoperative Sore Throat, Anesth pain Med., 5(3): 105-120.

15. Gupta SK, Tharwani S, Singh DK et al. (2012): Nebulized magnesium for prevention of postoperative sore throat. $\mathrm{Br}$ J Anaesth., (9): 108-168. 